\title{
DIMENSIONAMENTO DE UM LEITO DE PARTÍCULAS COM APLICABILIDADE DO PROCESSO DE ADSORÇÃO
}

\section{ARTIGO ORIGINAL}

SIARA, Linston Romão ${ }^{1}$, SANTOS, Caio Delano Couto², SABINO, Carlos Henrique Barbosa $^{3}$, VALE, Carolina Azevedo ${ }^{4}$ PEREIRA, Caroline Ramos ${ }^{5}$, QUEIROZ, Thauany Oliveira ${ }^{6}$, SANTOS, Alexsander Saves dos ${ }^{7}$

SIARA, Linston Romão. Et al. Dimensionamento de um leito de partículas com aplicabilidade do processo de adsorção. Revista Científica Multidisciplinar Núcleo do Conhecimento. Ano. 06, Ed. 09, Vol. 06, pp. 110-129. Setembro 2021. ISSN: 2448-0959, Link de acesso: https://www.nucleodoconhecimento.com.br/engenhariaquimica/processo-de-adsorcao,

DOI: 10.3274/nucleodoconhecimento.com.br/engenharia-quimica/processo-de-adsorcao

\section{RESUMO}

O processo de adsorção é uma das operações unitárias utilizadas na indústria química, visto que, possui a capacidade de remoção de substâncias contaminantes e indesejáveis. O principal objetivo desse artigo é desenvolver um leito fixo de partículas que demonstre o processo de adsorção com uso do carvão ativado para remoção de substâncias deletéria. A temática aborda uma pesquisa experimental, demonstrando os principais mecanismos para construção estrutural do leito de partículas, dos testes realizados, das análises físico-químicas e dos métodos analíticos como avaliação do processo de adsorção adeptos com a literatura. O leito

\footnotetext{
${ }^{1}$ Bacharel em Química Industrial e Acadêmico de Engenharia Química.

${ }^{2}$ Acadêmico de Engenharia Química.

${ }^{3}$ Acadêmico de Engenharia Química.

${ }^{4}$ Acadêmico de Engenharia Química.

${ }^{5}$ Acadêmico de Engenharia Química.

${ }^{6}$ Acadêmico de Engenharia Química.

${ }^{7}$ Orientador.
}

RC: 97862

Disponível em: https://www.nucleodoconhecimento.com.br/engenhariaquimica/processo-de-adsorcao 
de partículas, portanto, comprovou a eficácia do carvão ativado para remoção de substância deletéria de presente na água durante o processo de adsorção.

Palavras-chaves: Operação unitária, Leito de partículas, Adsorção.

\section{INTRODUÇÃO}

As operações unitárias é um mecanismo de separação muito utilizado nas engenharias de processos (GARSIDE, 1994). Dessa forma, compreender essa temática é essencial para gestão de qualidade na produção industrial.

A ideia do Processo de Separação está intrinsecamente ligada ao sistema de Operação Unitária. Arthur D Little foi o pioneiro na sistematização de ensino dos processos químicos, visto que em 1915, introduziu na Engenharia Química a definição de Operações Unitárias, como sendo toda a unidade do processo que gera transformações na matéria em seu estado químico e físico (RUBEGA, 2000).

Dentre os inúmeros processos unitários, destacam-se os processos de separação por adsorção, que acontece por meio de um leito de partícula que funciona através do escoamento do fluído (fase móvel) através da fase sólida particulada (fase estacionária) (CATELAM, 2015). Nesta perspectiva, um dos principais objetivos de um leito de partículas (recheio) é promover o contato íntimo entre as fases envolvidas no processo (fase fluida gasosa e/ou líquida com a fase estacionária/partículas ou entre diferentes fases fluidas). A Figura 1 representa $o$ esquema de um leito fixo de partículas. 
Figura 1: Leito fixo de partículas.

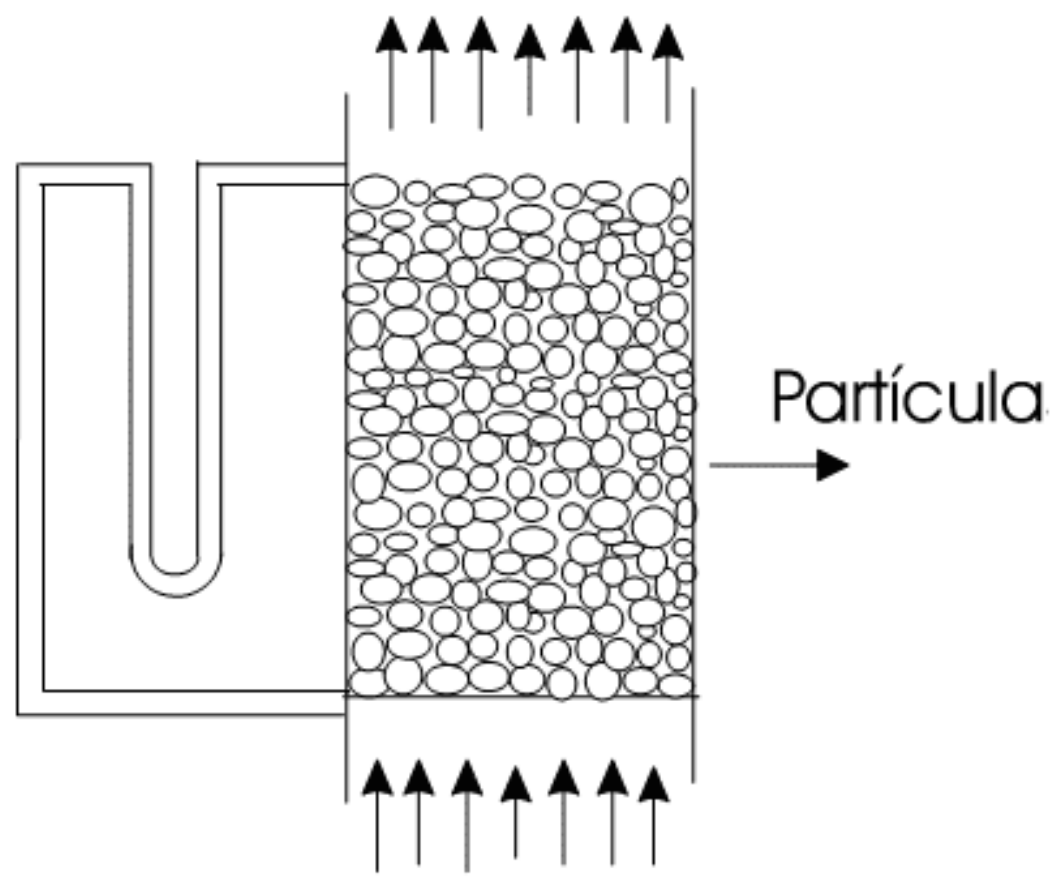

\section{Flı lidn}

Fonte: UFSC - Universidade Federal de Santa Catarina (2009).

A adsorção é uma das aplicações do leito fixo de partículas, onde ocorre um processo físico-químico em que as partículas ficam aprisionadas na superfície de substâncias sólidas. O processo de adsorção classifica-se de duas classes: o físico, sem aplicação de reações química, e o químico com utilização de reação química. Neste caso, a reação irá influenciar a velocidade de absorção influenciando o sistema (LIMA, 2020).

Quanto aos fenômenos físicos e químicos destaca-se em ambos dois elementos fundamentais para compreensão do processo de separação por adsorção, ou seja, - adsorvatos, substâncias gasosas ou liquidas que ficam presas na superfície, e adsorventes, substância sólida que causa a retenção da substância (CATELAM, 2015). Segue na Figura 2 a descrição do comportamento microscópico do processo de adsorção recorrente ao carvão ativado.

RC: 97862

Disponível em: https://www.nucleodoconhecimento.com.br/engenhariaquimica/processo-de-adsorcao 
Figura 2: Processo de absorção recorrente ao carvão ativado.

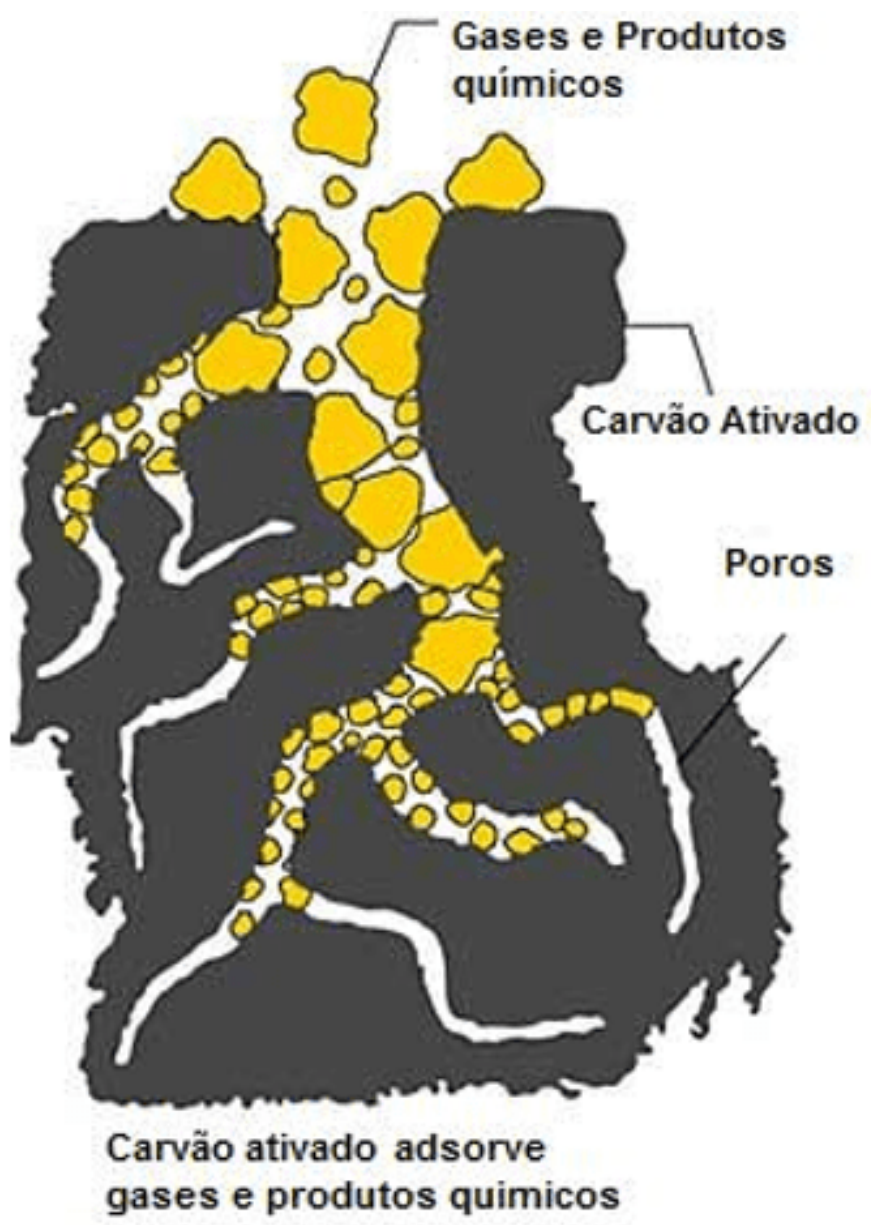

Fonte: Ribas (2016).

Outros parâmetros levados em consideração durante o processo de adsorção é a solubilidade e o fenômeno de difusão de determinados compostos em duas fases distintas e insolúveis. Nesta perspectiva, dentre os inúmeros materiais para execução do processo de adsorção, enfatiza-se o carvão ativado que é um método bem conhecido para a remoção de contaminantes, porém o alto custo do carvão ativado restringe o seu uso. Desta forma, alternativas mais baratas acabam sendo priorizadas (COELHO, 2014).

Nas indústrias, usualmente é utilizada a adsorção gasosa, que recupera compostos, minimiza a contaminação do ar, é utilizada na preparação de matéria prima, 
processos de transformação de insumos, assim como purificação de produtos acabados. Ela é denominada pela transferência de um material (componente) em uma composição gasosa para uma composição líquida absorvente, devido a diferença de concentração e solubilidade, entre as fases (LEITE, 2005).

A diferença de volatilidade, geralmente existente, entre os componentes da fase líquida e da gasosa, proporciona somente uma adsorção de componentes mais pesados, sem haver perdas da mistura por evaporação (ROITMAN, 2002).

Em concordância com Roitman (2002), para que ocorra o processo de adsorção, há uma necessidade da proporção líquido/vapor mínima, que quanto maior essa proporção, melhor será o processo de adsorção, pois o líquido ficara com uma concentração menor no composto que será adsorvido. Já a relação da proporção, que ocorre por meio inverso, vapor/líquido mínima, é denominada esgotamento.

O carvão ativado é um grande removedor de moléculas poluentes, as quais se concentram em sua superfície e são removidas. Com isso a escolha do mesmo para se fazer a filtração, envolve considerações importantes a serem avaliadas, como a temperatura, regeneração, líquido a ser filtrado e o custo do processo (FREITAS, 2020). Seguem na Figura 3, os elementos contidos no carvão ativado que possibilita o processo de adsorção.

RC: 97862

Disponível em: https://www.nucleodoconhecimento.com.br/engenhariaquimica/processo-de-adsorcao 
Figura 3: Elementos contidos no carvão ativado.

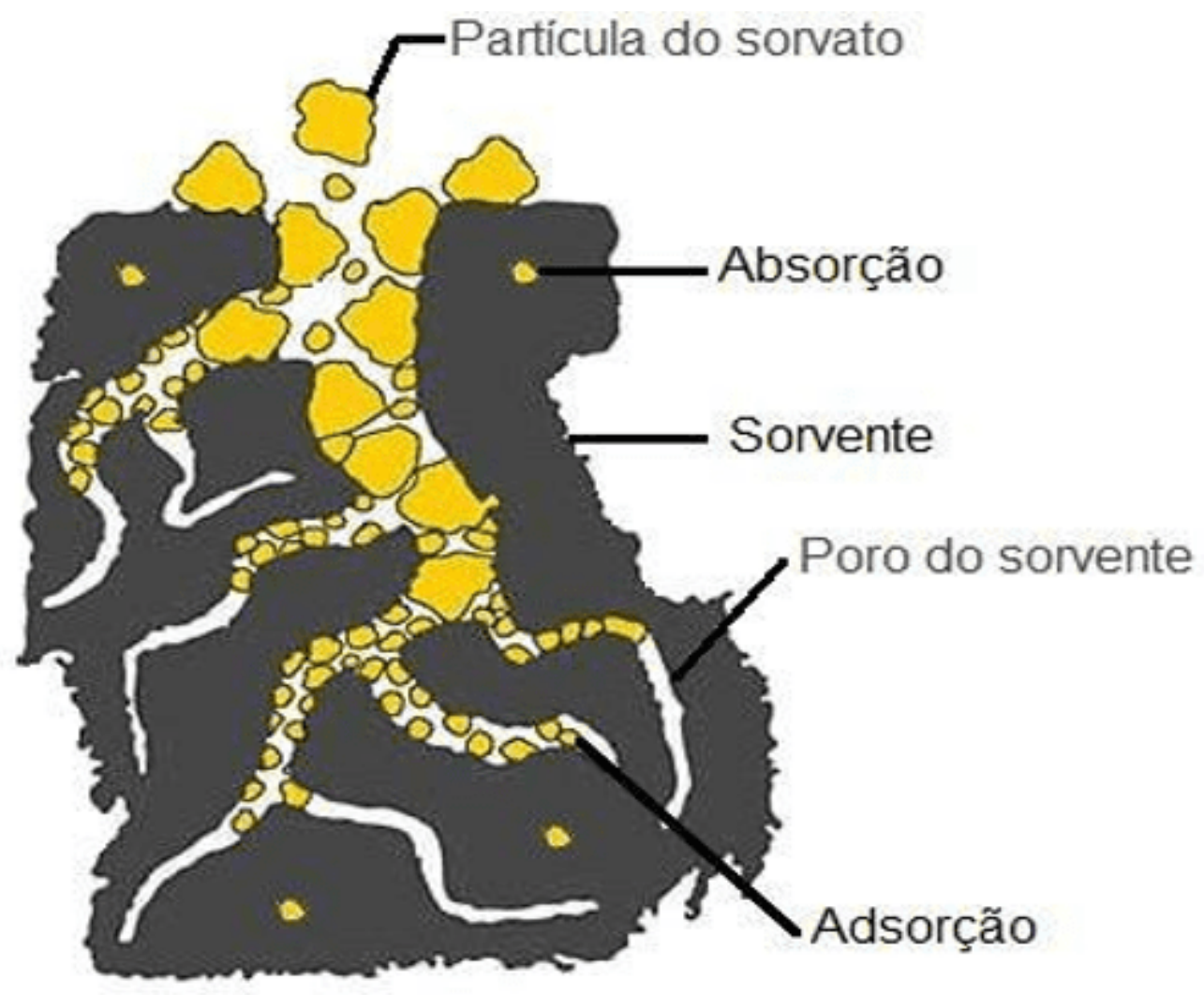

Fonte: Ribas (2016).

Devido ao Carvão Ativado ser um material poroso adsorvente, de origem natural, muito usado para filtração e purificação de materiais como água e outros líquidos, foi definido a utilização do mesmo como meio para realização do processo de adsorção do presente projeto.

O trabalho, portanto, teve como objetivo principal desenvolver mecanicamente um leito de partículas que possibilita compreender o processo de adsorção por meio do carvão ativado, ou seja, analisar a sua capacidade em remover substâncias deletérias como matéria orgânica e inorgânica, ademais, permite entender conceitos e aplicabilidades industriais adeptos aos métodos analíticos e teóricos. 


\section{METODOLOGIA}

O projeto foi realizado na Universidade Brasil em Fernandópolis-SP, situada na Estrada F-1, s/n, Fazenda Santa Rita, entre os meses de setembro a outubro de 2020. O projeto teve como base uma pesquisa experimental, com o objetivo de construir um leito de partículas que demonstre o processo de adsorção em um meio poroso com carvão ativado, cuja propriedade promove a remoção de substâncias orgânicas. Dessa forma, desenvolveu-se um itinerário representado pela Figura 4 no formato de fluxograma com todas as principais etapas da metodologia empregada.

Figura 4: Fluxograma das principais etapas do projeto.

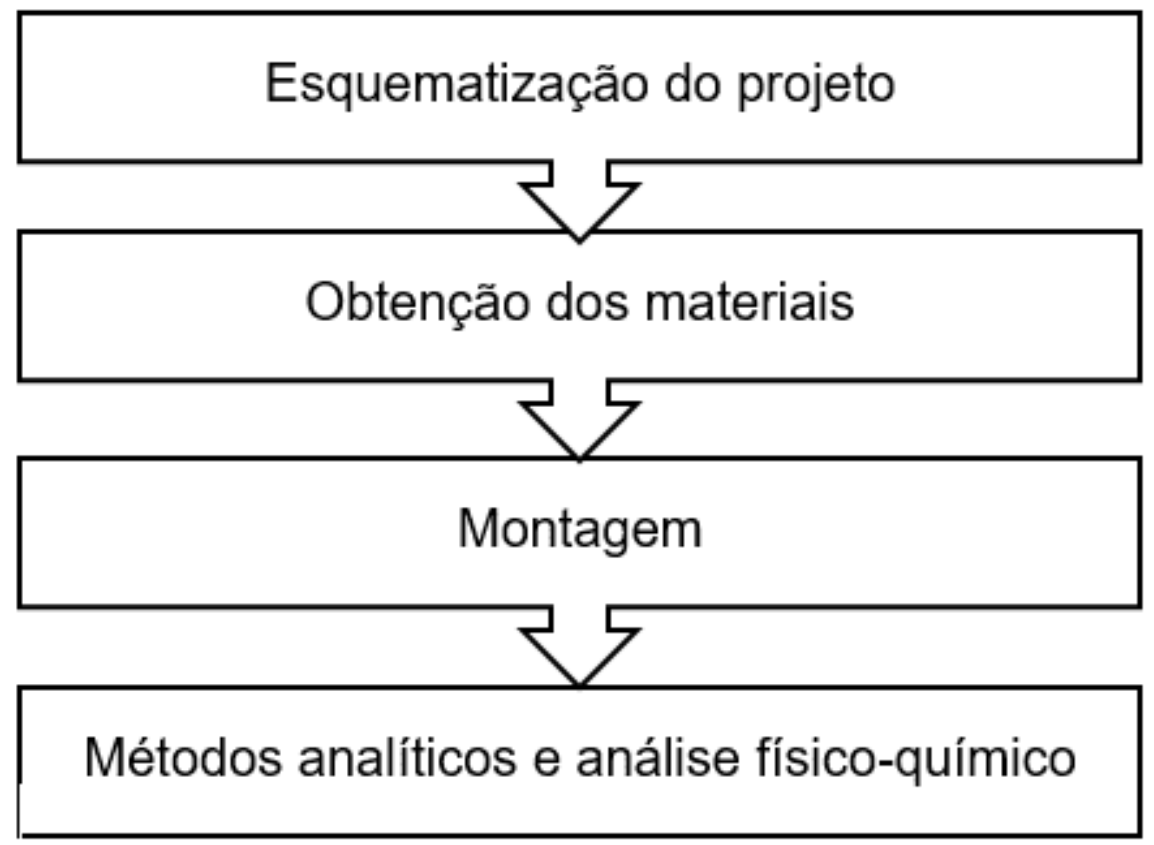

Fonte: Autoria própria.

O estadista britânico Winston Churchill (1874-1965) afirmava que o planejamento é essencial para elaboração de qualquer trabalho. Dessa forma, criou-se uma esquematização do projeto a fim de avaliar toda a estrutura do projeto. A Figura 5 representa a esquematização do projeto. 
Figura 5: Desenho esquematizado do leito de partículas.

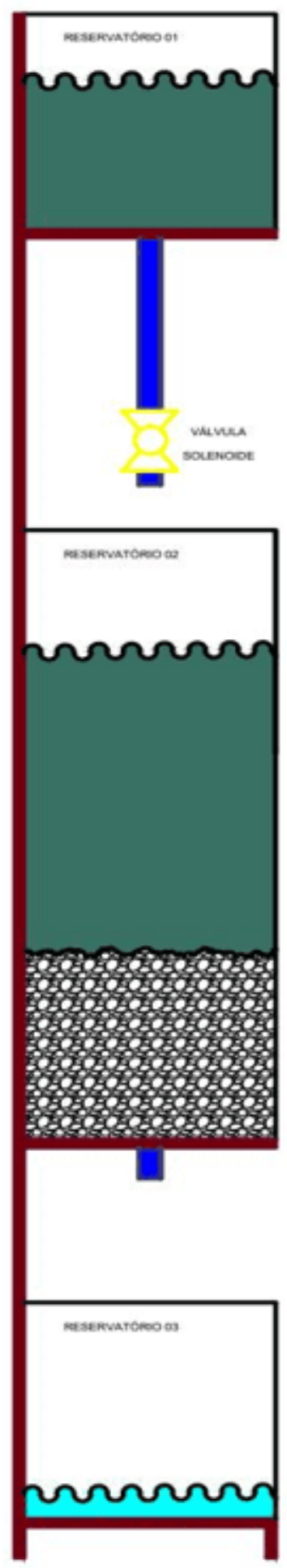

Fonte: Autoria própria.

RC: 97862

Disponível em: https://www.nucleodoconhecimento.com.br/engenhariaquimica/processo-de-adsorcao 


\subsection{MONTAGEM ESTRUTURAL DO LEITO DE PARTÍCULAS}

Todos os materiais formam adquiridos com os recursos próprios. Portanto, segue pormenorizados no Quadro 1 todos os itens utilizados na construção do leito de partículas que caracteriza o processo de adsorção.

Quadro 1: Itens utilizados na montagem do leito de partículas

\begin{tabular}{|l|l|l|}
\hline Materiais & Unidade & Quantidade \\
\hline Reservatórios de Vidro & un & 3 \\
\hline Abraçadeira borboleta & un & 3 \\
\hline Mangueira cristal & $\mathrm{m}$ & 1 \\
\hline Flanges & un & 2 \\
\hline Solenóide & un & 1 \\
\hline Adaptador de Flanges & un & 1 \\
\hline Parafuso Phillips & un & 6 \\
\hline Silicone & un & 2 \\
\hline Cantoneira mão francesa & un & 4 \\
\hline Chapa de zinco & $\mathrm{m} 2$ & 0,0225 \\
\hline Carvão ativado & $\mathrm{kg}$ & 1 \\
\hline Policloreto de alumínio & $\mathrm{ml}$ & 100 \\
\hline Biocida & $\mathrm{ml}$ & 100 \\
\hline Solenóide & un & 1 \\
\hline
\end{tabular}

Fonte: Autoria própria.

Inicialmente realizaram cortes no vidro, obtendo oito placas no formato retangular de $0,14 \mathrm{~m} \times 0,13 \mathrm{~m}$, três placas de 0,14 x 0,14 e quatro placas de 0,14 m x 0,40 m. Em seguida, utilizando silicone coloram-se as quatro placas retangulares de $0,14 \mathrm{~m} x$ $0,13 \mathrm{~m}$ em uma placa de $0,14 \mathrm{~m} \times 0,14 \mathrm{~m}$ e as outras quatro placas de $0,14 \mathrm{~m} \times 0,13$ $\mathrm{m}$ em uma das placas de $0,14 \mathrm{~m} \times 0,14 \mathrm{~m}$, e repetiu o processo com a última placa

RC: 97862

Disponível em: https://www.nucleodoconhecimento.com.br/engenhariaquimica/processo-de-adsorcao 
de $0,14 \mathrm{~m} \times 0,14 \mathrm{~m}$ e as quatro placas de $0,14 \mathrm{~m} \times 0,40 \mathrm{~m}$. Com isso, obtiveram-se três reservatórios o superior, o intermediário e o inferior, ambos com abertura no topo.

Em seguida, conectaram esses reservatórios utilizando mangueira cristal, flange e válvula solenoide e como forma de amarração utilizou-se abraçadeiras. Com isso, realizaram-se furos na chapa de zinco com diâmetros que permita a passagem do fluído e que retém o carvão ativado e o instalou no reservatório intermediário. Como forma de suporte para os reservatórios utilizou-se cantoneiras de mão francesa. Ao término da montagem preencheu-se o reservatório intermediário com 0,000784m3 de carvão ativado.

A Figura 6 demonstra as principais etapas de montagem estrutural do leito de partículas.

Figura 6: Fluxograma das principais etapas de montagem.
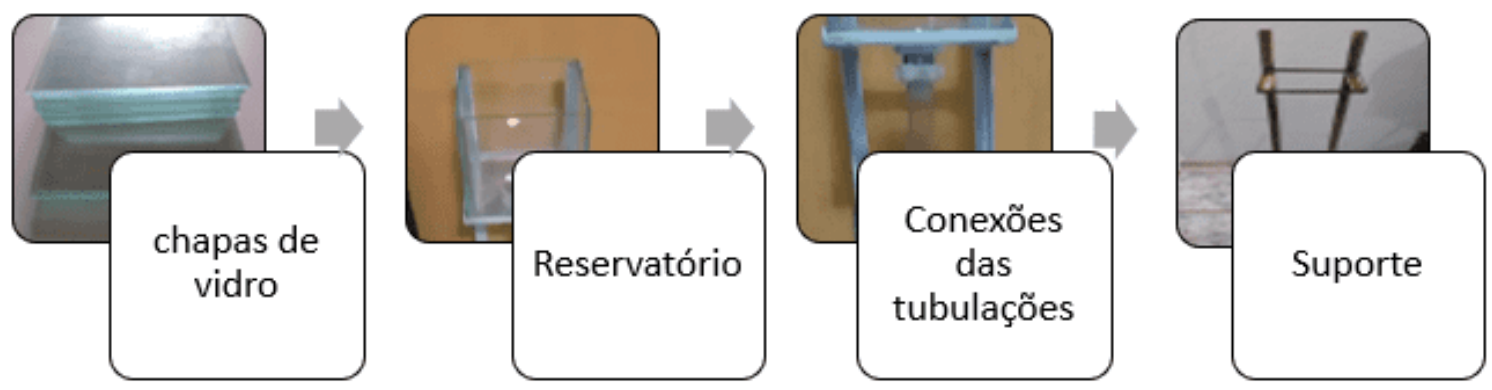

Fonte: Autoria própria.

A Figura 7 representa o projeto finalizado, isto é, o leito de partículas com características do processo de adsorção com aplicação do carvão ativado como adsorvente. 
Figura 7: Leito de partículas finalizado.

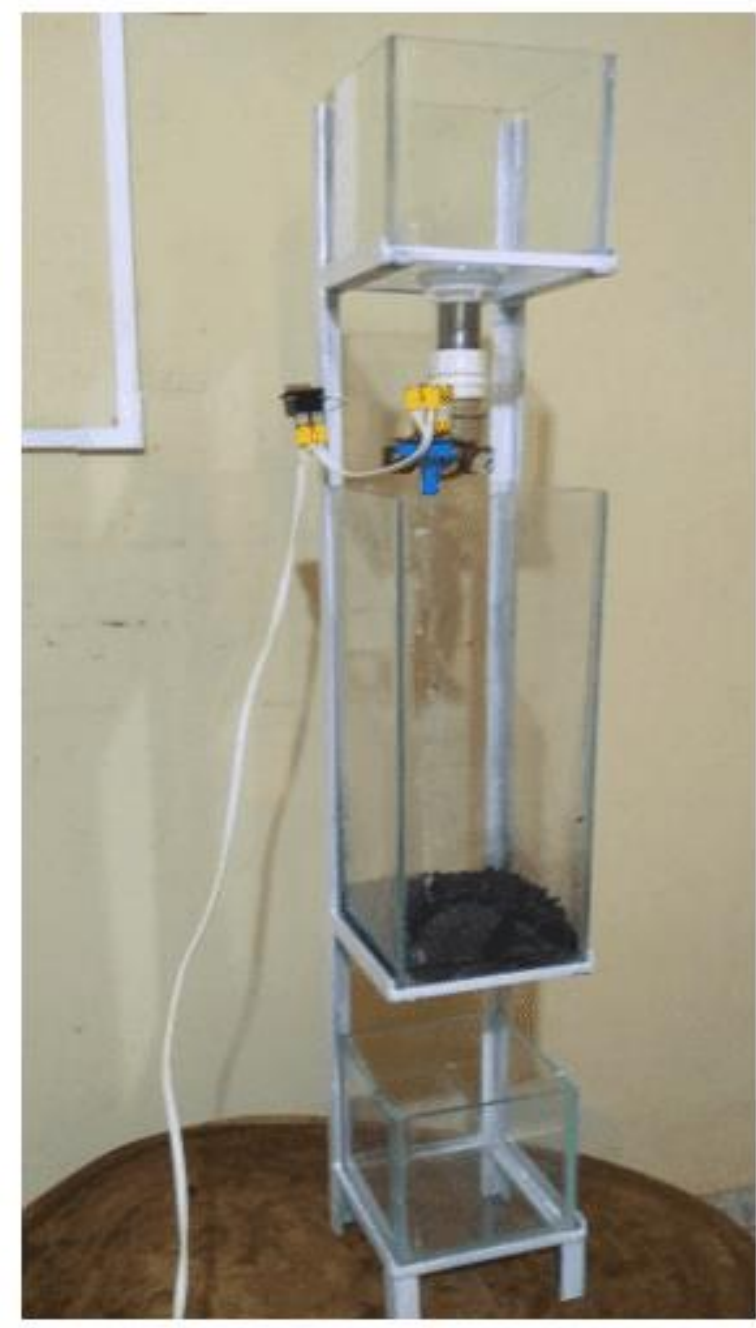

Fonte: Autoria própria.

\subsection{TESTES FísICO-QUímicos DA ÁGUA E DO LEITO DE PARTÍCULAS}

A fim de validar o projeto que caracteriza o processo de adsorção do carvão ativado e remoção de substâncias orgânicas, foi realizada uma série de testes físicoquímicos em um laboratório especializado no tratamento de água e esgoto da cidade de Iturama- MG no dia 18 de novembro de 2020.

RC: 97862

Disponível em: https://www.nucleodoconhecimento.com.br/engenhariaquimica/processo-de-adsorcao 
Inicialmente realizaram-se testes no corpo do leito de partículas verificando a ocorrência de vazamentos ou qualquer irregularidade na estrutura física.

Em seguida, foram realizados os testes físico-químicos que tiveram como objeto de estudo amostras de água contaminada com impurezas. Portanto, o uso de vidrarias e equipamento específicos permitiu a realização de análises como físicas, ou seja, condutividade e propriedades organolépticas como turbidez e as análises químicas como pH, alcalinidade média, Cloreto, Cloro. Portanto, o Quadro 2 exemplifica as análises e seus respectivos procedimento durante os testes.

Quadro 2: Análises físicas- químicas e seus respectivos procedimentos.

\begin{tabular}{|c|c|c|}
\hline Análises & Métodos & Definição \\
\hline $\begin{array}{l}\text { Condutividade } \\
\text { elétrica }\end{array}$ & Eletométrico & Utilizou-se um condutivímetro \\
\hline Turbidez & Nefelométrico & $\begin{array}{l}\text { Comparou-se a luz que atravessa uma } \\
\text { amostra sob condições definidas, com } \\
\text { a intensidade da luz atravessada por } \\
\text { um padrão de referência sob as } \\
\text { mesmas condições }\end{array}$ \\
\hline Cloro & Espectrofotometria & $\begin{array}{l}\text { Utilizou-se um espectrofotômetro, } \\
\text { previamente calibrado. }\end{array}$ \\
\hline Cloreto & Mohr & $\begin{array}{l}\mathrm{O} \text { íon cloreto é precipitado } \\
\text { quantitativamente pelo nitrato de prata } \\
\left(\mathrm{AgNO}_{3}\right) \text { na presença de cromato de } \\
\text { potássio }\left(\mathrm{K}_{2} \mathrm{CrO}_{4}\right)\end{array}$ \\
\hline pH & Eletrométricos & 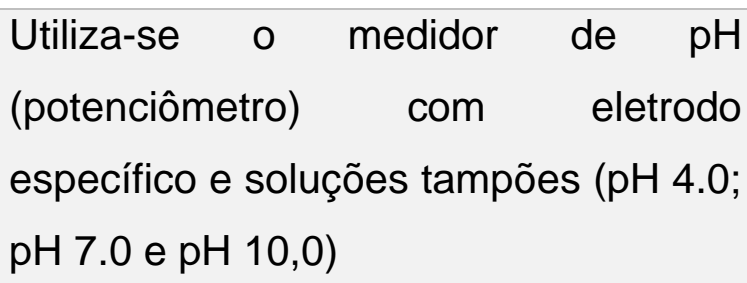 \\
\hline
\end{tabular}

RC: 97862

Disponível em: https://www.nucleodoconhecimento.com.br/engenhariaquimica/processo-de-adsorcao 


\begin{tabular}{|l|l|l}
\hline Alcalinidade média & Titulométricos & $\begin{array}{l}\text { Realizou-se uma titulação com uso de } \\
\text { fenolftaleína como indicador }\end{array}$
\end{tabular}

Fonte: Autoria própria.

A Figura 8 representa às amostras que foram realizadas as análises laboratoriais, isto é a água contaminada, antes do processo de adsorção e, água purificada após o processo.

Figura 8: Amostras de água, contaminada e purificada.

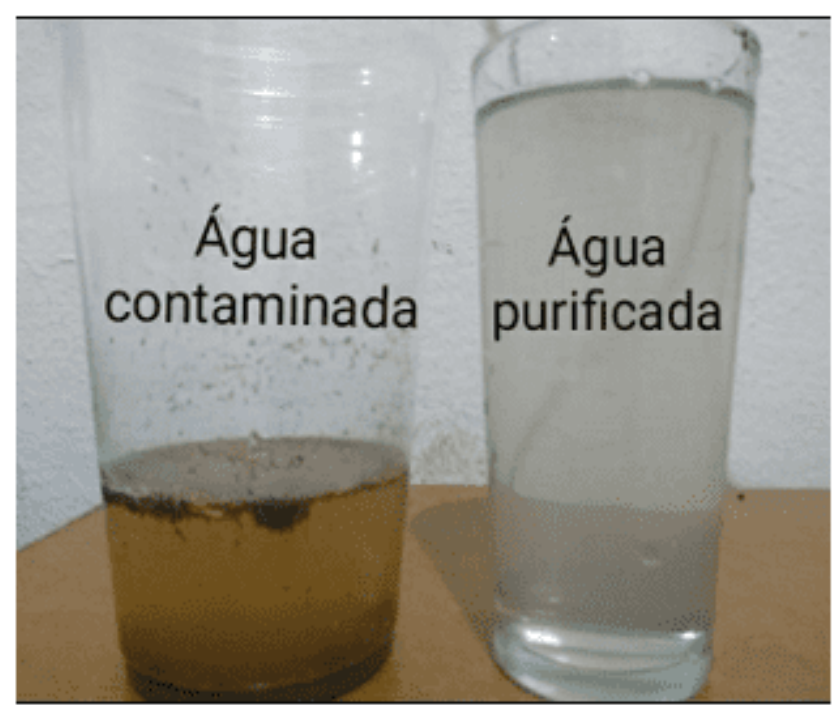

Fonte: Autoria própria.

\subsection{MÉTODOS ANALÍTICOS}

Como forma de complementação dos resultados o projeto adotou-se os métodos algébricos para compreensão do comportamento do fluído durante o processo de adsorção. Com isso, foi possível obter grandezas físicas importante, como vazão de alimentação, nível de porosidade do carvão ativado e a velocidade superficial e intersticial. 
Para obter a vazão de alimentação utilizou-se a Equação 1.

$$
Q=\frac{V}{t}
$$

Em que t é o tempo dado em $\mathrm{s}, V$ é o volume em $\mathrm{m}^{3}$ e o é a vazão $\mathrm{em} \mathrm{m}^{3} / \mathrm{s}$.

Outro parâmetro importante para o processo de adsorção é o nível de porosidade do carvão ativado, portanto, a Equação 2 demonstra a fórmula utilizada.

$$
\varepsilon=\frac{V_{o}}{V_{T}}
$$

Em que o $\varepsilon$ é a porosidade do carvão ativado é adimensional, o $V_{o}$ é o volume vazio dado em $\mathrm{m}^{3}$ e o ${ }^{V_{T}}$ é o volume total, essas duas últimas grandezas físicas estão associadas à coluna do leito de partículas que contém o carvão ativado.

Adotando a lei de Darcy de forma generalizada foi possível obter a velocidade superficial, a mesma está representada pela Equação 3.

$$
q=\frac{Q}{A}
$$

Em que $q$ é a velocidade superficial dada em $\mathrm{m} / \mathrm{s}$, é a vazão $\mathrm{em} \mathrm{m}^{3} / \mathrm{s}$ e $A$ é a área transversal da coluna.

Ao final, calculou-se a velocidade intersticial, ou seja, a velocidade pelo qual o fluído passa pelos espaços vazios entre os poros (interstício) utilizando a Equação 4. 


$$
v=\frac{q}{\varepsilon}
$$

Em que $V$ é a velocidade intersticial dada em $\mathrm{m} / \mathrm{s}, q$ é a velocidade superficial dada em $\mathrm{m} / \mathrm{s}$ e $\varepsilon$ é a porosidade do carvão ativado é adimensional.

\section{RESULTADOS E DISCUSSÃO}

O leito de partículas é um tipo de operação que permite compreender o fenômeno de adsorção através das propriedades do carvão ativado. Vale salientar que para o desenvolvimento dos resultados adotou-se considerações, ou seja, o projeto demonstrou um processo de adsorção do tipo físico, isto é, não ocorrem reações químicas durante a separação dos compostos e a fase fluida comporta-se como fluído newtoniano, onde a viscosidade é constante (água).

Neste experimento o carvão ativado é o adsorvente, visto que suas propriedades físico-químicas possuem uma grande influência na taxa e capacidade de adsorção. Ademais, utilizaram-se meios nos quais facilitam e aceleram o processo, portanto, à adição de reagentes como policloreto de alumínio e de biocidas promovem ações como coagulação e eliminação de organismos contaminantes, respectivamente.

A priori é fulcral pontuar que o desenvolvimento do desenho esquematizado do leito de partículas tem como objetivo atuar como um mecanismo de montagem, pois possibilita de forma ampla a identificação e visualização de todos os constituintes do dispositivo, como reservatórios e tubulações. Dessa forma, nota-se que todos os componentes foram fixados de forma estratégica a fim de evitar qualquer tipo de quadro deletério.

Os resultados foram desenvolvidos baseados em dois eixos principais, os métodos analíticos, que permite entender o comportamento do fluído por meio da vazão, da velocidade superficial e intersticial e o nível de porosidade, outrossim, são as análises químicas que possibilita avaliar a eficiência do leito de partículas no 
processo de adsorção. Somando a isso, compararam-se os dados com a literatura a fim de confiabilizar os resultados. O Quadro 3, representa todos os cálculos referente ao fluído no processo de adsorção.

Quadro 3:Desenvolvimento dos métodos analíticos

[caption

$$
\text { id="attachment_97875" }
$$

$$
\text { align="aligncenter" }
$$

width="698"]

\begin{tabular}{|c|c|c|c|}
\hline Incógnitas & Fórmulas & Substituições & Resultados \\
\hline Vazão & $Q=\frac{V}{t}$ & $Q=\frac{0,002}{62}$ & $3.23 \times 10^{-5} \mathrm{~m}^{3 / \mathrm{s}}$ \\
\hline Porosidade & $\varepsilon=\frac{V_{o}}{V_{T}}$ & $\varepsilon=\frac{7.056 \times 10^{-3}}{7,84 \times 10^{-3}}$ & 0.9 \\
\hline Velocidade superficial & $q=\frac{Q}{A}$ & $q=\frac{3.23 \times 10^{-5}}{0,0196}$ & $0.00165 \mathrm{~m} / \mathrm{s}$ \\
\hline Velocidade intersticial & $v=\frac{q}{\varepsilon}$ & $v=\frac{0.00165}{0,9}$ & $0.00183 \mathrm{~m} / \mathrm{s}$ \\
\hline
\end{tabular}

Fonte: Autoria própria.

O principal objetivo dos métodos analíticos é o entendimento do comportamento do fluído e da partícula durante o processo de adsorção promovido pelo carvão ativado. Portanto, utilizando-se a Equação 1 obteve-se uma vazão volumétrica de $3.23 \times 10^{-5} \mathrm{~m}^{3} / \mathrm{s}$.

.Segundo Dervanoski (2012), na tese sobre aplicação da coluna de adsorção em leito fixo para remoção de compostos BTX relacionado aos efluentes petroquímicos sintéticos, a vazão representada em testes foi de $6.67 \times 10^{-7} \mathrm{~m}^{3} / \mathrm{s}$.

Sabendo que o leito poroso existe espaços vazios, em outros termos, zonas sem partículas, pode-se calcular a quantidade de poros presente na superfície através da Equação 2 no qual obteve-se um valor de 0.9 , de modo geral, significa as distâncias entre os poros. Conforme estudos desenvolvidos por Dervanoski (2012), sobre 
adsorção com o objeto de estudo o carvão ativado a porosidade encontrada foi de 0.41 .

A fim de analisar o comportamento do fluído obtém-se por meio da Equação 30 valor da velocidade superficial de $0.00165 \mathrm{~m} / \mathrm{s}$ e por meio da Equação 4 aufere-se a velocidade intersticial de $0.00183 \mathrm{~m} / \mathrm{s}$. . Ao se comparar ambas as velocidades se observam que a velocidade intersticial é superior a velocidade superficial, isso ocorre pois segundo Renha (2015) a presença de sólidos promove uma redução da área de escoamento, portanto, "é necessário que os sólidos sejam comprimidos na menor área (poros) ", permitindo a preservação do escoamento do fluído.

Outro eixo que possibilita à comprovação da eficiência do processo de adsorção é às análises laboratoriais realizadas por uma empresa de tratamento de água. Dessa forma, foram efetuadas análises físicas e químicas das amostras antes e depois do processo de adsorção.

Todos os resultados das análises das amostras estão representados através de métodos gráficos. Portanto, os gráficos demonstram de forma concisa os valores das análises da condutividade, da turbidez, do Cloro, Cloreto, do pH e alcalinidade média das amostras antes e depois do fenômeno de adsorção, ademais permite realizar um comparativo com os valores estipulado pelo Ministério da Saúde adeptos a Portaria no 2.914/2011 que definia importância da potabilidade para o consumo humano.

De uma forma lacônica a água contaminada inicialmente apresentou um pH 5,57, isto é, segundo a literatura é classificado como ácido, ademais o cloro foi de $0.13 \frac{\mathrm{mg}}{\mathrm{L}}$,

e o cloreto, ou seja, a presença de sais com . e, consequentemente a condutividade de $929,9 \frac{\mathrm{mg}}{\mathrm{L}}$, , isso se deve a alta presença de 
compostos inorgânicos. Ademais, observou-se uma alcalinidade média de ${ }^{40 \frac{\mathrm{mg}}{\mathrm{L}}}$ e uma turbidez de 37 UT, tal valor é influenciado devido a presença de partículas em suspensão, como microorganismo.

Após o processo de adsorção obteve-se novos parâmetros, isto é, obteve-se aumento do $\mathrm{pH}$ de 6.81 ainda ácido, porém, não se aferiu uma mudança da alcalinidade média de $40 \mathrm{mg} / \mathrm{L}$, visto que, permaneceu sem alterações. Ademais, evidenciou-se uma redução não só na quantidade de cloro e do cloreto, resultando $\mathrm{em}^{0,01 \frac{\mathrm{mg}}{\mathrm{L}}} \mathrm{e}^{14.2 \frac{\mathrm{mg}}{\mathrm{L}}}$ respectivamente, mas também da condutividade elétrica $\operatorname{com}^{128.22 \frac{\mathrm{mg}}{\mathrm{L}}}$ e da turbidez de 27 UT, essa redução foi possível devido à capacidade do carvão ativado em realizar o processo de adsorção de substâncias como cloro, sais e matéria orgânica.

Portanto, os gráficos permitem uma comparação das amostras antes, água bruta e depois do processo de adsorção, água filtrada. Dessa forma, o Gráfico 1 representa o valor do pH, o Gráfico 2 o valor do cloro, o Gráfico 3 demonstra os resultados dos cloretos, o Gráfico 4 os valores da turbidez, o Gráfico 5 ressalta os valores da alcalinidade e o Gráfico 6 os valores referentes a condutividade elétrica.

RC: 97862

Disponível em: https://www.nucleodoconhecimento.com.br/engenhariaquimica/processo-de-adsorcao 
Gráfico 1: Comparativo do $\mathrm{pH}$.

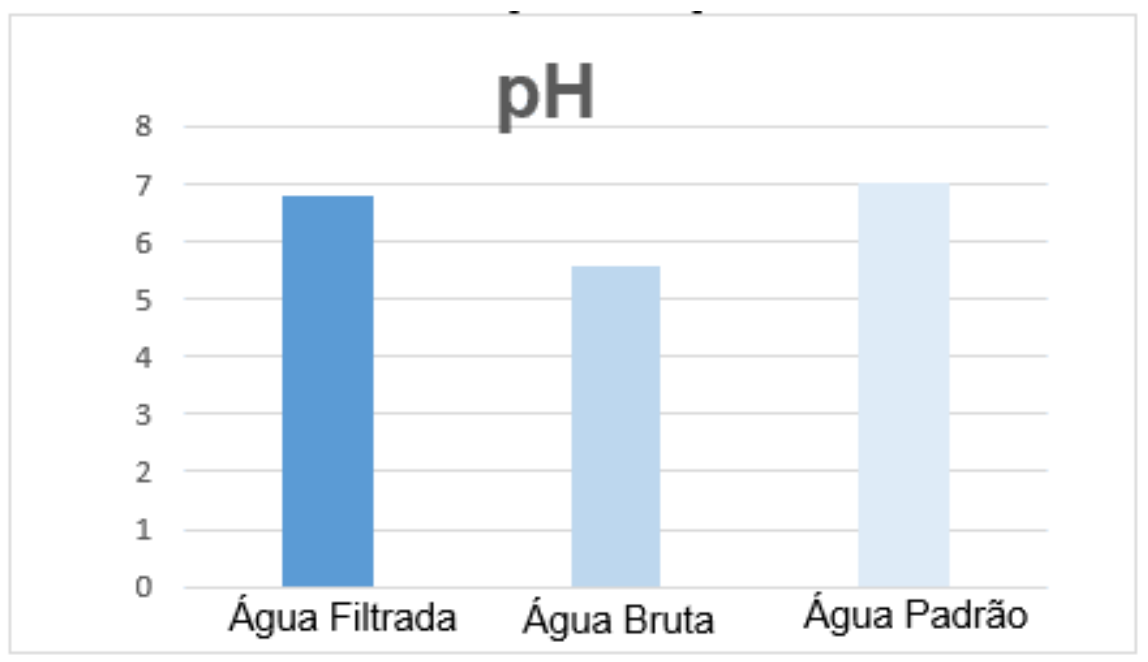

Fonte: Autoria própria.

Gráfico 2: Comparativo da quantidade de cloro.

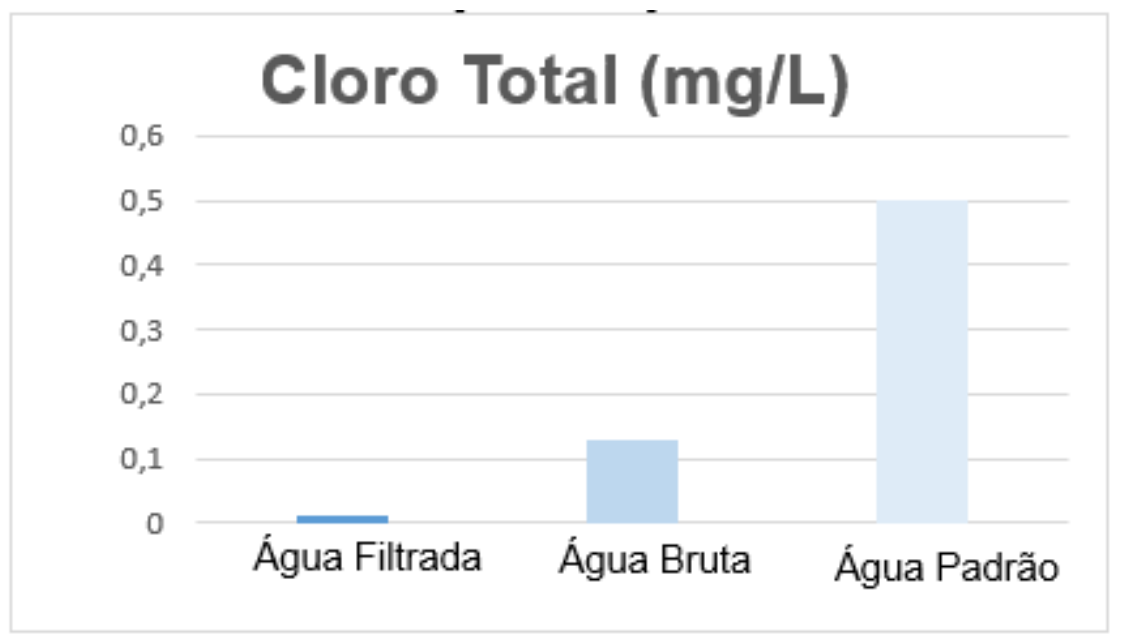

Fonte: Autoria própria.

RC: 97862

Disponível em: https://www.nucleodoconhecimento.com.br/engenhariaquimica/processo-de-adsorcao 
Gráfico 3: Comparativo da quantidade de cloreto (sais).

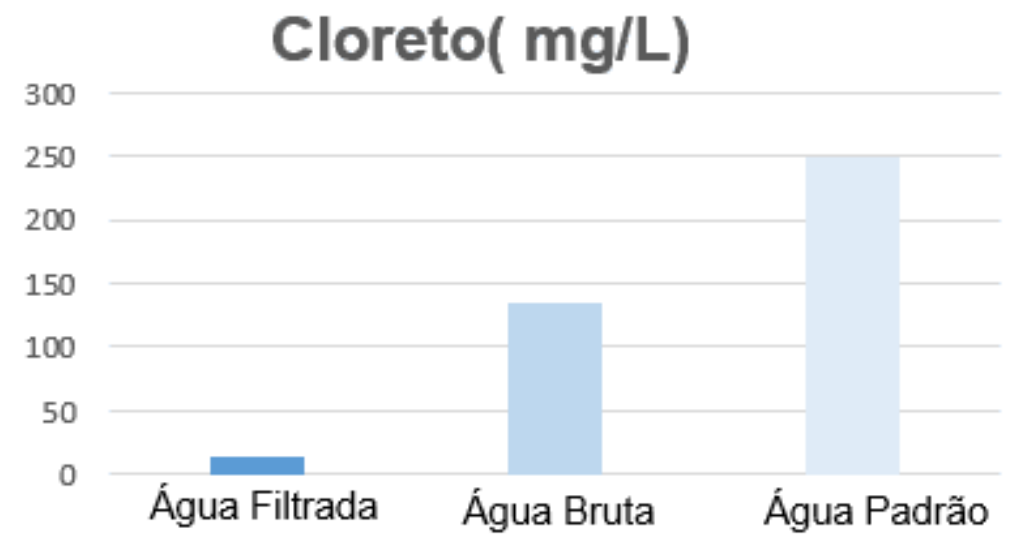

Fonte: Autoria própria.

Gráfico 4: Comparativo da turbidez.

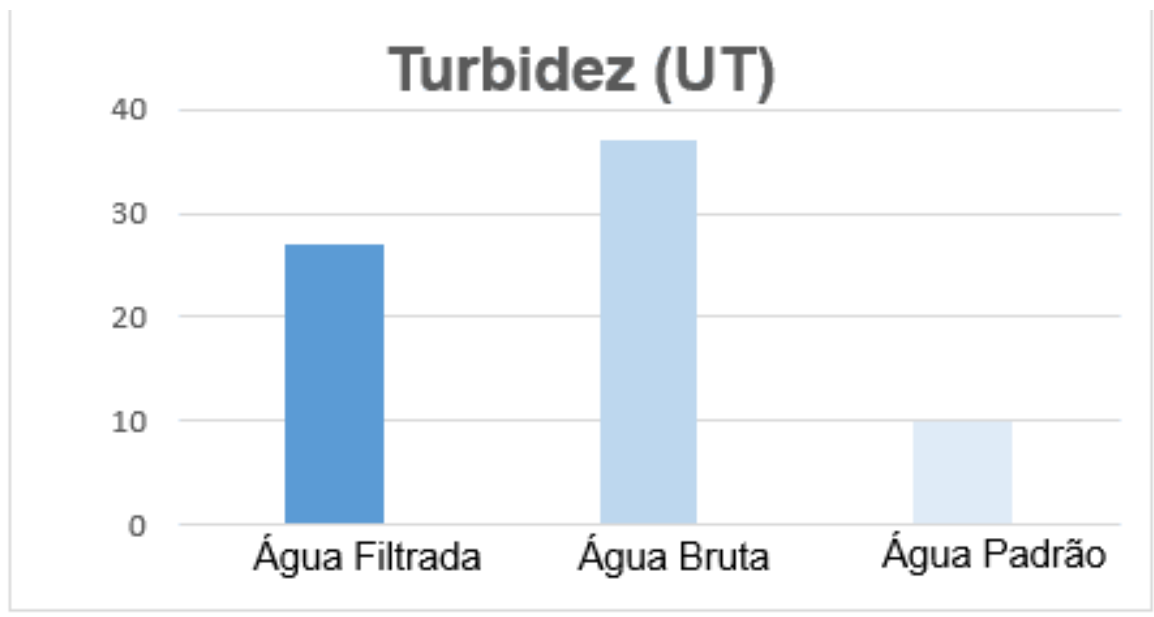

Fonte: Autoria própria.

RC: 97862

Disponível em: https://www.nucleodoconhecimento.com.br/engenhariaquimica/processo-de-adsorcao 
Gráfico 5: Comparativo nível de alcalinidade média.

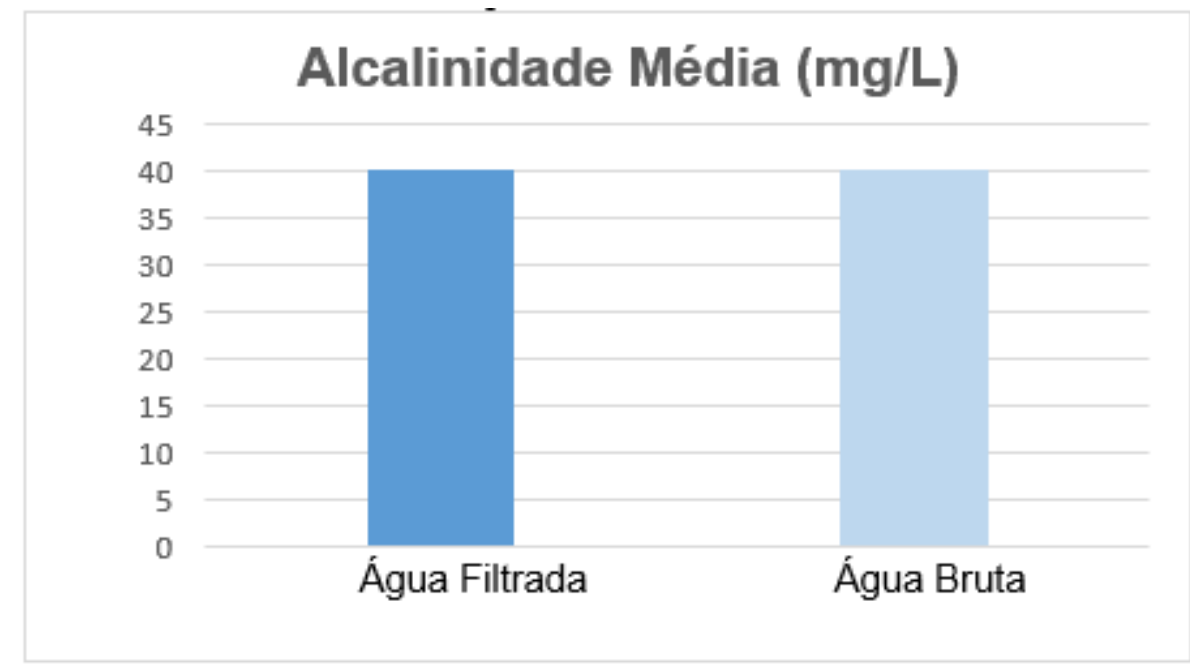

Fonte: Autoria própria.

Gráfico 6: Comparativo da condutividade elétrica.

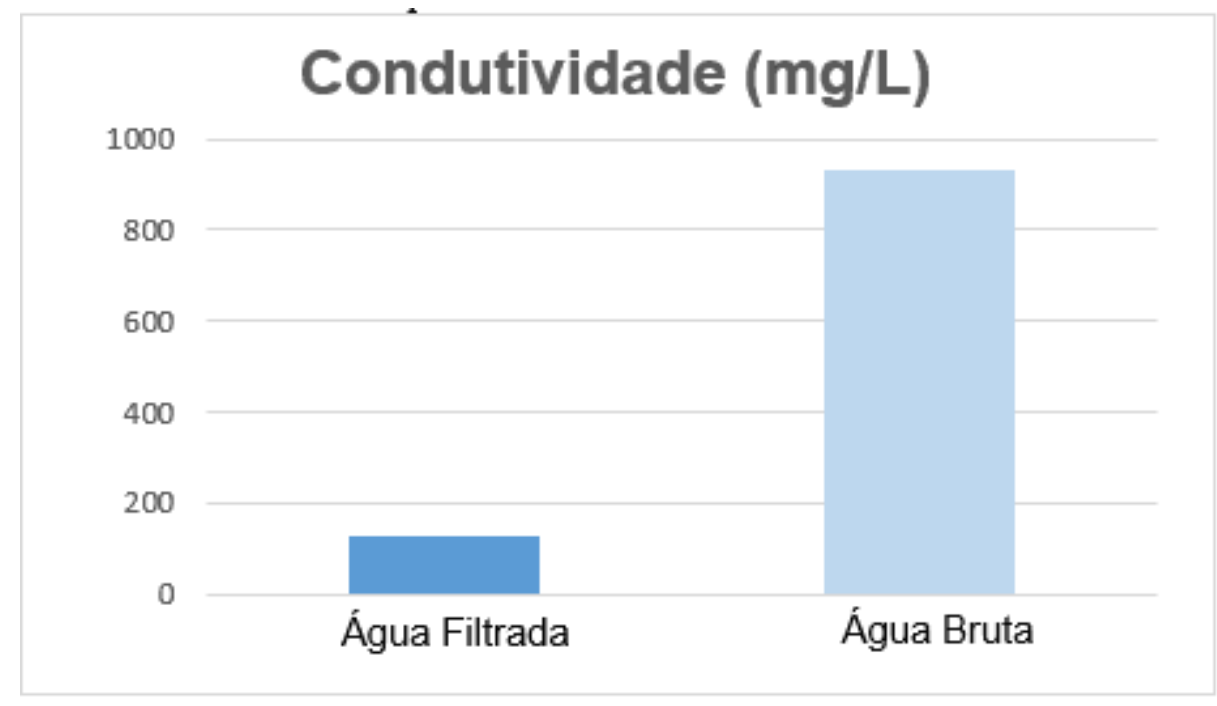

Fonte: Autoria própria.

Ao interpretar os dados representados nos gráficos permite comparar as amostras antes do processo de adsorção com presença de substâncias deletérias em excesso, que são as maiores influenciadoras das modificações de parâmetros físicoquímicos e depois do processo de adsorção, dessa forma, pode-se observar a RC: 97862

Disponível em: https://www.nucleodoconhecimento.com.br/engenhariaquimica/processo-de-adsorcao 
capacidade do carvão ativado em separar ou reduzir determinados compostos contaminados que estão em quantidade exorbitante na água.

\section{CONCLUSÃO}

O artigo, portanto, atendeu todos os objetivos previstos, uma vez que discorreu sobre a importância do processo de adsorção na indústria química. Destarte, o dimensionamento de um leito fixo de partículas com aplicação do carvão ativado como meio de adsorção funcionou de forma adequada e dentro da normalidade, ou seja, sem vazamentos ou quaisquer outras deformidades. Ademais, demonstrou-se eficiente na remoção de substâncias deletérias, como matéria orgânica e inorgânica presente na água contaminada.

Visando uma melhor sapiência dos resultados dividiu-se para fins didáticos em dois eixos principais, o primeiro, através das determinações analíticas, buscando compreender o comportamento do fluido durante o processo e, o segundo, por meio dos métodos laboratoriais cujo objetivo é comprovar a eficácia do carvão ativado em realizar o processo de adsorção através das análises físico-químicas.

O leito de partículas apresentou grandezas físicas que agem de forma intrínseca umas as outras. Com isso, evidenciou uma vazão volumétrica, ou seja, uma alimentação do fluído de $3.23 \times 10^{-5} \mathrm{~m}^{3} / \mathrm{s}$. ativado apresentou uma porosidade de 0.9, que permitiu obter uma velocidade intersticial de $0.00183 \mathrm{~m} / \mathrm{s}$, , e uma velocidade superficial de $0.00165 \mathrm{~m} / \mathrm{s}$. Ao se comparar as análises da amostra antes e depois do processo de adsorção evidenciou-se um aumento do $\mathrm{pH}$, porém constatou-se uma redução da quantidade cloro, cloreto, condutividade elétrica e turbidez. Ademias, a quantidade de alcalinidade média permaneceu inalterável. Infere-se, portanto, que mesmo que tais parâmetros não estejam dentro das diretrizes estabelecidas para o consumo $n^{\circ}$ 2.914/2011, comprovou-se a capacidade do carvão ativado em consonância com 
meios alternativos como adição de policloreto de alumínio e biocidas em realizar o processo de adsorção de substâncias como, sais, matéria orgânica e cloro que em excesso promove um quadro deletério.

Em síntese, o leito de partículas apresentou dados e resultados adeptos a literatura, atingindo assim, resultados almejados.

\section{REFERÊNCIAS}

CATELAM, Kelly. Absorção, 2015. Disponível em: <https://slideplayer.com.br/slide/6928669/>. Acessado em 02 de nov. de 2020.

COELHO, Gustavo Ferreira et al. Uso de técnicas de adsorção utilizando resíduos agroindustriais na remoção de contaminantes em águas. Journal of Agronomic Sciences, Umuarama, v.3, n. especial, p.291-317, 2014.

DERVANOSKI, Adriana. Aplicação de coluna de adsorção em leito fixo para remoção de compostos BTX multicomponentes presentes em efluentes petroquímicos, 2012.

Disponível:<https://repositorio.ufsc.br/xmlui/bitstream/handle/123456789/100668/309 613.pdf?sequence=1\&isAllowed $=y>$. Acessado em: 15 nov. 2020 .

FREITAS, Leizer. Carvão ativo: breve histórico e estudo de sua eficiência na retenção de fármacos. Disponível em: <http://www.unilago.edu.br/revista/edicaoatual/Sumario/2014/downloads/6.pdf>. Acessado em: 12 de out. de 2020.

GARSIDE, Josh (Ed). Separation Technology: The Next Tem Years, Institution of Chemical Engineers, UK, 1994.

LEITE, André Búrigo; BERTOLI, Sávio Leandro; BARROS, António André Chivanga. Absorção química de dióximo de nitrogênio (NO2). Engenharia Sanitária Ambiental, v. 10, p. 49-57, 2005. Disponível em: < 
https://www.scielo.br/j/esa/a/VST8jBkcwMFLwmN7jZXNfrp/?format=pdf\&lang=pt>. Acessado em 12 de nov. de 2020.

LIMA, Cleane. $2020 . \quad$ Ddsorção, em: <https://www.educamaisbrasil.com.br/enem/quimica/adsorcao>. Acessado em 12 de out. de 2020.

MINISTÉRIO DA SAÚDE. Portaria ํㅜ2.914, de 12 de dezembro de 2011. Disponível em:

https://bvsms.saude.gov.br/bvs/saudelegis/gm/2011/prt2914_12_12_2011.html>. Acessado em 02 de nov. de 2020.

RENHA, Julia Frota. Simulação do processo de injeção de soluções poliméricas viscoelásticas na escala de reservatório, 2015. Disponível em: <https://www.maxwell.vrac.puc-rio.br/27000/27000_1.PDF>. Acessado em: 15 nov. 2020.

RIBAS, Marielen Cozer. A remoção de corantes têxteis pelo processo de adsorção utilizando carvão ativado produzido a partir de subprodutosagroindustriais -estudos em batelada e coluna de leito fixo, 2016. Disponível em: < https://docplayer.com.br/59417933-Universidade-federal-do-rio-grande-do-sulescola-de-engenharia-programa-de-pos-graduacao-em-engenharia-quimica.html>. Acessado em 12 de out. de 2020.

ROITMAN, Valter. Operações Unitárias, 2011. Disponível em: <https://pt.slideshare.net/tabVlae/apostila-deformaooperaesunitrias>. Acessado em 21 de out. de 2020 .

RUBEGA, Critina Cimarelli; PACHECO, Décio. Aformação da mão-de-obra para a indústria química: uma retrospectiva histórica. Ciencias \& Educação (Bauru), v.6, p. 2000. 151-166, Disponível em: < https://www.scielo.br/j/ciedu/a/KDMGBH9C6TKTmXNZKkpfVVt/?lang=pt\&format=pdf >. Acessado em 08 de out. de 2020.

RC: 97862

Disponível em: https://www.nucleodoconhecimento.com.br/engenhariaquimica/processo-de-adsorcao 
Enviado: Agosto, 2021.

Aprovado: Setembro, 2021.

Disponível em: https://www.nucleodoconhecimento.com.br/engenhariaquimica/processo-de-adsorcao 